Saudi Journal of Biomedical Research

Abbreviated Key Title: Saudi J Biomed Res ISSN 2518-3214 (Print) |ISSN 2518-3222 (Online)

\title{
L-Arginine Modulates Glucose Transport Mechanisms in Glycerol- Induced Kidney Injury in Wistar Rats
}

Kolawole I. Ajiboye*, Chizitara Nkwopara

Department of Physiology, Benjamin S Carson School of Medicine, Babcock University, Nigeria

DOI:10.36348/SJBR.2019.v04i09.003 $\quad$ | Received: 19.09.2019| Accepted: 27.09.2019| Published: 30.09 .2019

*Corresponding author: Kolawole I. Ajiboye

Abstract

Glucose handling and metabolism is disturbed in acute kidney injury; L-arginine is a component of nitric oxide (NO) which aids the delivery of blood to tissues. This study focused on investigating the underlying effect that L-arginine would have on glucose handling and GLUT-4 expression in rats with acute kidney injury. Oral glucose tolerance test was used to assess the rat's ability to regulate glucose metabolism, glucose utilization by the cells and how quickly glucose is cleared from the blood. Insulin tolerance test was used to assess insulin resistance and the sensitivity of target organs to insulin, as well as the rate of glucose clearance from the blood. Glucose transporter 4 expression was assessed via ELISA. Results showed that glucose clearance from the blood was more effective and rapid in the arginine-treated groups when compared to the control group. L-arginine induced rapid insulin-like action which was effective after thirty minutes of oral glucose loading in both groups treated with arginine but the effect was not long-lasting. Similar result was observed from the insulin tolerance test, again indicating an insulin-like action of arginine. L-arginine produced no marked difference in GLUT-4 expression across the various groups showing that the insulin-like activity observed may not be via the activation of GLUT-4 channels or exocytosis of GLUT-4 proteins to the plasma membranes of insulin target organs. This study showed that L-arginine exhibits a rapid but un-sustained insulin-like action in glucose metabolism by clearing glucose from the blood and this action is not via the activation of GLUT-4 channels on plasma membranes.

Keywords: Arginine, GLUT-4, nitric oxide, Kidney injury, Insulin tolerance, Glucose tolerance.

Copyright @ 2019: This is an open-access article distributed under the terms of the Creative Commons Attribution license which permits unrestricted use, distribution, and reproduction in any medium for non-commercial use (NonCommercial, or CC-BY-NC) provided the original author and source are credited.

\section{INTRODUCTION}

The kidney is critical in maintaining a stable internal environment by regulating the body fluid volume, maintaining electrolyte balance, and excreting potentially toxic metabolic end products. Glomerular filtration, tubular reabsorption, and tubular secretion are processes involved in urine formation resulting in production of approximately 1.5 liter urine per day for an adult. Glomerular infiltration involves the ultrafiltration of plasma in the glomerulus, and the filtrates, including water, salts, glucose and urea, are accumulated in the urinary space of Bowman's capsule. Tubular reabsorption involves taking back approximately $99 \%$ of the filtrates into the blood, while tubular secretion involves the transport of substances such as $\mathrm{K}^{+}, \mathrm{H}^{+}$, ammonium, creatinine, and urea into the urine.

The kidneys have a major role in glucose and insulin metabolism. In humans, renal glucose production contributes approximately $25 \%$ to the systemic glucose production and also, renal glucose uptake contributes about $20 \%$ to systemic glucose removal [1]. Glucose homeostasis in the kidney is regulated by insulin and it is mediated via Glucose Transporter (GLUT) proteins [2].

Glucose Transporter Type 4 (GLUT-4) is an insulin-responsive glucose transporter which is expressed in the membranes of the skeletal muscles, heart and adipose tissue cells. These tissues are insulin sensitive and they respond to an increase in blood insulin levels by a rapid and reversible uptake of glucose. Upon insulin stimulation, GLUT-4 is translocated to the plasma membrane of body cells, where it facilitates the uptake of glucose.

Acute kidney injury (AKI), previously called acute renal failure, is characterized by an abrupt decline in renal function, resulting in an inability to secrete waste and maintain electrolyte and water balance, and is associated with high risks of morbidity and mortality [3]. Insulin is also metabolized by the kidneys hence 
loss of kidney metabolic functions could lead to insulin resistance along with abnormal glucose production and cellular glucose transport [4]. Insulin resistance is defined as a decreased biological action of insulin at its target organs for any given blood concentration of insulin [5]. Reduction in renal functions can also increase the half-life of insulin in circulation and this can lead to hypoglycemic events [1].

L-arginine is a semi-essential amino acid that is important for a number of biochemical and physiological functions in protein synthesis. It has been shown to enhance the release of a number of hormones including corticotrophin releasing hormone, prolactin, growth hormone, somatostatin, insulin, glucagon, cortisone and aldosterone; some of which have been implicated in tissue fibrosis [6]. L-arginine is also involved in decreased platelet aggregation, and decreased blood pressure. The net effect is improved blood circulation in the body, especially in the extremities and in genitalia [7]. The amino acid Larginine provides molecular substrate for the generation of nitric oxide (NO). A decreased bioavailability of (NO) is a crucial factor for the development of endothelial dysfunction and, furthermore, seems to play an important role in the development of insulin resistance. Therefore, it has been proposed that increasing blood flow by the action of (NO) on resistant vessels could facilitate the delivery of glucose and insulin and thereby contribute to overall glucose transport [8]. In acute kidney injury, glucose handling is disturbed; L-arginine is a component of nitric oxide (NO) which aids the delivery of blood to tissues. This study focused on investigating the underlying effect that L-arginine would have on GLUT-4 expression in the kidney injured rat. The aim of this study is to investigate the effects of L-arginine supplementation on
Glucose Transporter Type 4 (GLUT 4) expression in acute kidney injury in Wistar rats.

\section{MATERIALS AND METHODS Animals}

Twenty (20) male albino Wistar rats weighing between $120 \mathrm{~g}-150 \mathrm{~g}$ were used. They were fed with pelletized rat feed purchased from Sabina feed house, Lagos. They had free access to tap water. They were procured and housed at ambient temperature and humidity within the animal handling facility of the Department of Physiology, Benjamin Carson (Snr.) School of Medicine, and Babcock University, Nigeria. The study is an in-vivo experimental work. The rats' weights were recorded once a week, for two (2) weeks, during the period of acclimatization and after commencement of the experimental study. At the end of the $2^{\text {nd }}$ week, acute kidney injury (AKI) was induced with intra-muscular injection of glycerol (50\% solution, $5 \mathrm{ml} / \mathrm{kg}$ body weight; [9]. Two days after the induction, AKI was confirmed by checking the serum creatinine (SCr; e-labscience, China) levels of the rats. Abnormally high levels of serum creatinine indicated the presence of kidney injury in the rats (normal Scr = 0.6 to $1.2 \mathrm{mg} / \mathrm{dl}$; Yin et al. [10]. After confirmation of $\mathrm{AKI}$, the rats received graded doses of L-arginine $(500 \mathrm{mg} / \mathrm{kg}$ and $50 \mathrm{mg} / \mathrm{kg}$ ) orally for eight (8) days. The effects of L-arginine supplementation on GLUT 4 expression, insulin tolerance and glucose tolerance in the kidney injury wistar rat model were then investigated via various assays. The animals were sacrificed by cervical dislocation. Ethical approval for the study was obtained from the Babcock University Health Research Ethics Committee (BUHREC).

\section{Animal Grouping and Treatment Schedule}

The rats were randomly distributed into four (4) groups of five (5) rats each as seen below:

Table-1: Animal grouping and treatment schedule

\begin{tabular}{|l|l|}
\hline GROUPS & TREATMENT \\
\hline Group 1 (Positive Control) & Normal feed and water \\
\hline Group 2 (L-arginine, $500 \mathrm{mg} / \mathrm{kg})$ & $\begin{array}{l}\text { Glycerol-induced AKI with high dose of L-arginine } \\
(100 \mathrm{ml} / \mathrm{kg} \text { body weight p.o.) }\end{array}$ \\
\hline Group 3 (L-arginine, $50 \mathrm{mg} / \mathrm{kg})$ & $\begin{array}{l}\text { Glycerol-induced AKI with low dose of L-arginine } \\
(10 \mathrm{ml} / \mathrm{kg} \text { body weight p.o. })\end{array}$ \\
\hline Group 4 (Negative Control) & Glycerol-induced AKI without any other treatment \\
\hline
\end{tabular}

\section{Determination of Blood Glucose Levels}

Blood was drawn from the tails and blood glucose level was checked with the Accu-check glucometer kit, and the values were recorded in milligrams per deciliter ( $\mathrm{mg} / \mathrm{dl})$.

\section{Induction of Acute Kidney Injury (AKI)}

AKI was induced by injecting $5 \mathrm{ml} / \mathrm{kg}$ of glycerol (50\% in distilled water) into the muscles of both hind limbs. Control animals were injected with an equal volume of normal saline $(5 \mathrm{ml} / \mathrm{kg}$, ) via intramuscular injection [11].

\section{Insulin Tolerance Test}

The insulin tolerance test was performed using human insulin (Humulin) and an Accu-check glucometer kit. The animals were fasted for four (4) hours before insulin administration. The baseline blood glucose level was determined first with the Accu-check glucometer kit; then insulin ( 0.5 units $/ \mathrm{kg}$ body weight) was administered via injection subcutaneously [12]. Blood glucose concentration $(\mathrm{mg} / \mathrm{dl})$ was monitored at thirty (30) minutes intervals for the next two hours. 


\section{Oral Glucose Tolerance Test}

The animals were fasted overnight. Their baseline blood glucose level was checked and recorded $(\mathrm{mg} / \mathrm{dl})$. Exogenous glucose $(2 \mathrm{~g} / \mathrm{kg}$ body weight) was then administered by injection (i.p.). Blood glucose levels were again determined at thirty (30) minutes interval for a total of one hundred and eighty (180) minutes.

\section{Determination of Glut-4 Expression}

Gastrocnemius muscles from the left leg and the contralateral limb were excised, dissected, rinsed in iced cold Phosphate buffer solution (PBS) $\left(0.1 \mathrm{M}, \mathrm{P}^{\mathrm{H}}\right.$ =7.4) and frozen for GLUT-4 assays. The gastrocnemius muscles were weighed and the weight in grams $(\mathrm{g})$ of each muscle was multiplied by five (5) to determine the volume of PBS in milliliters (ml) to homogenize each muscle in. The homogenate was centrifuged at $3000 \mathrm{rpm}$ for ten $(10)$ minutes at $4^{\circ} \mathrm{C}$. The supernatant was extracted by decantation and quantified for GLUT-4 expression using GLUT-4 ELISA kit.

\section{STATISTICAL ANALYSIS}

Statistical analysis was carried out using Graph-Pad Prism 5.1 software. Comparisons between the groups was performed by one-way analysis of variance (ANOVA), followed by Student NewmanKeuls (SNK) test for significant difference. The data was expressed as mean \pm standard error of mean (SEM). $\mathrm{p}<0.05$ was considered as significant.

\section{RESULTS}

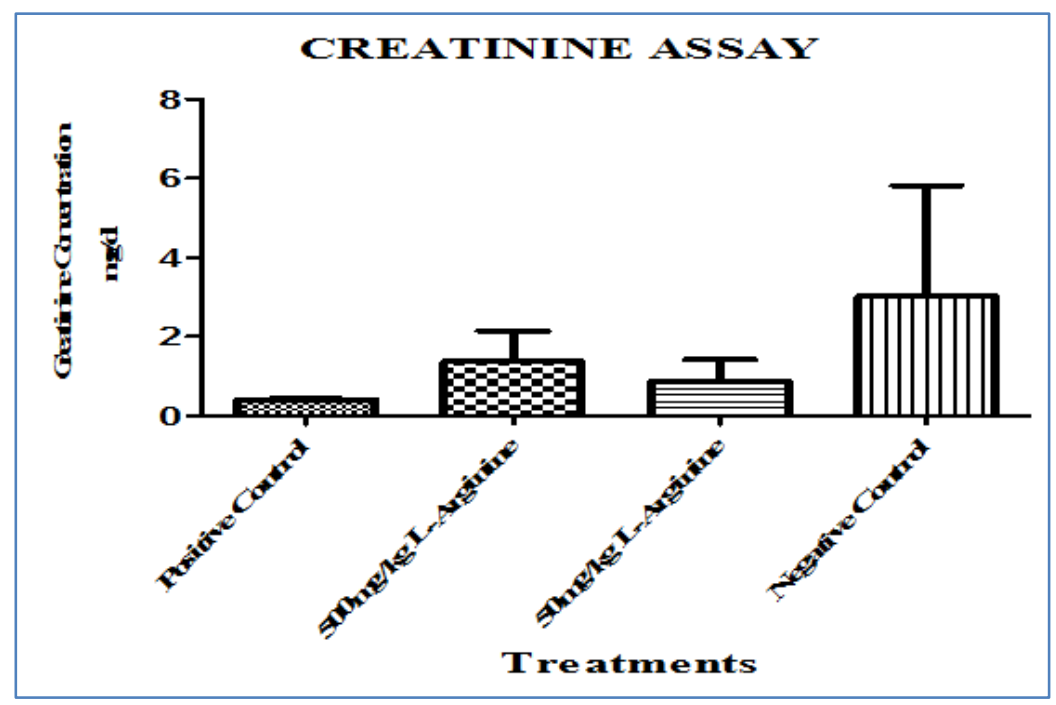

Fig-1: Effects of L-Arginine on serum creatinine in rats with AKI.

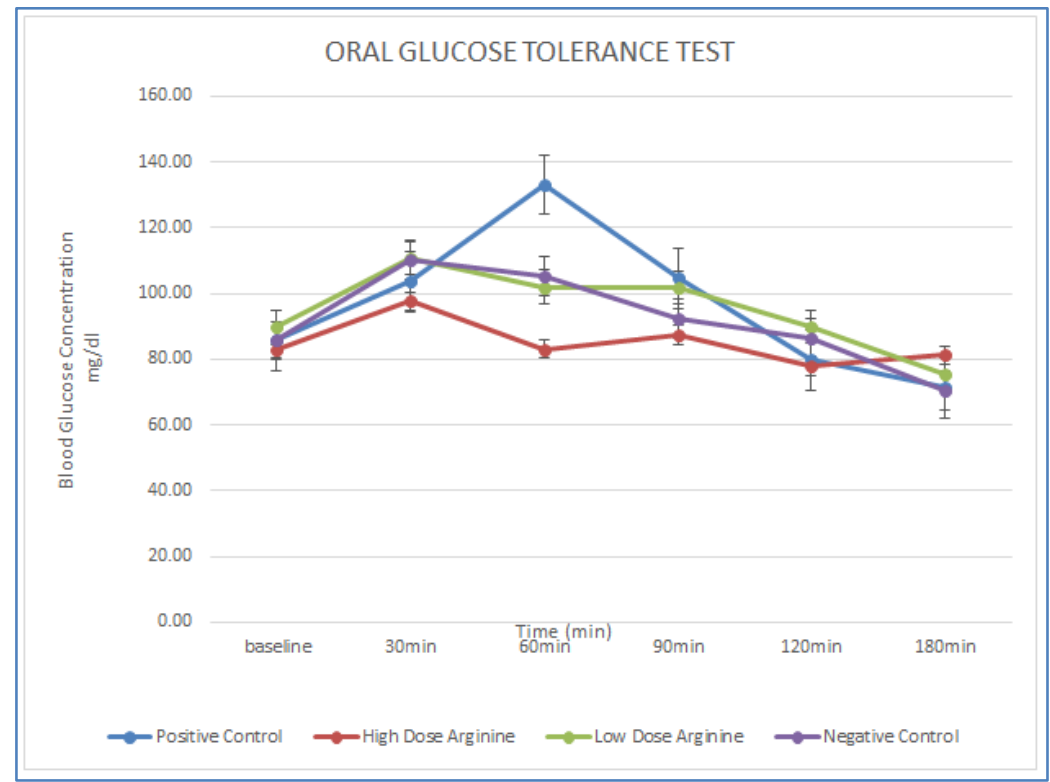

Fig-2: Effect of L-Arginine on glucose tolerance in rats with AKI 
Table-2: Effect of L-arginine on insulin tolerance in rats with acute kidney injury

\begin{tabular}{|l|l|l|l|l|}
\hline Time & Positive Control & $\begin{array}{l}\text { High Dose L- } \\
\text { Arginine (500mg/kg) }\end{array}$ & $\begin{array}{l}\text { Low Dose L- } \\
\text { Arginine (50mg/kg) }\end{array}$ & Negative Control \\
\hline Baseline & $86.43 \pm 2.43$ & $91.33 \pm 4.06$ & $120.67 \pm 3.83^{*}$ & $146.33 \pm 7.96^{*}$ \\
\hline 30 minutes & $68.34 \pm 3.34$ & $44.67 \pm 5.36$ & $95.33 \pm 7.37^{*}$ & $80.33 \pm 5.05$ \\
\hline 60 minutes & $43.05 \pm 9.05$ & $77.00 \pm 7.06^{*}$ & $93.33 \pm 5.41^{*}$ & $54.33 \pm 5.65$ \\
\hline 90 minutes & $34.61 \pm 8.61$ & $89.00 \pm 7.82^{*}$ & $105.33 \pm 5.60^{*}$ & $77.33 \pm 6.48$ \\
\hline 120 minutes & $28.83 \pm 3.83$ & $89.33 \pm 3.10^{*}$ & $116.00 \pm 4.07^{*}$ & $63.50 \pm 6.50^{*}$ \\
\hline
\end{tabular}

Values are expressed as mean \pm SEM $(n=6)$ and are statistically significantly different at $(\mathrm{P}<0.05$ or less $)$.

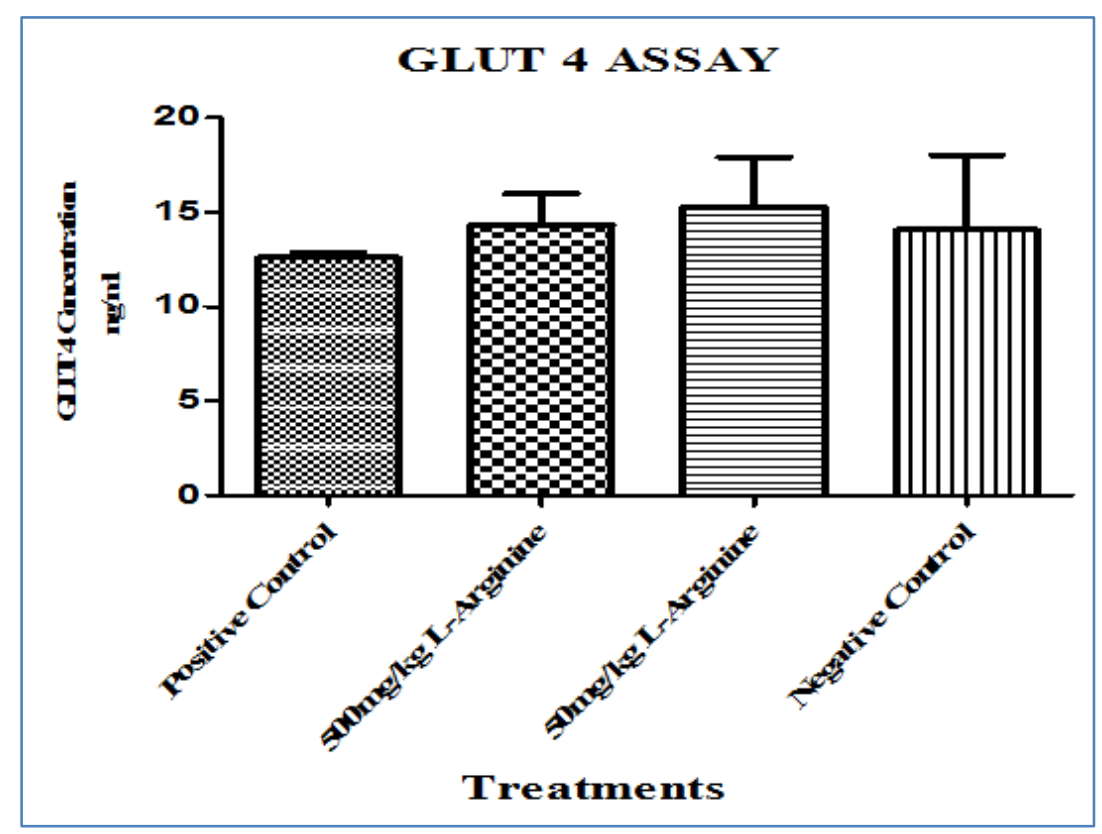

Fig-3: Effects of L-Arginine on GLUT-4 expression in rats with AKI

\section{DISCUSSION}

Acute kidney injury (AKI) was induced in the experimental rats using glycerol $(50 \%$ solution, $5 \mathrm{ml} / \mathrm{kg}$ body weight). There were elevated serum creatinine levels in the groups that received glycerol treatment, indicating the presence of kidney injury. In acute kidney injury, glucose handling and metabolism is disturbed; L-arginine is a component of nitric oxide (NO) which aids the delivery of blood to tissues. This study focused on investigating the underlying effect that L-arginine would have on glucose handling and GLUT4 expression in rats with acute kidney injury. The objective of this study was to determine how L-arginine will affect glucose delivery to cells along with blood and by what mechanism.

Oral glucose tolerance test (OGTT) is used to assess the body's ability to regulate glucose metabolism through glucose utilization by the cells of the body and how quickly glucose is cleared from the blood. From the present study, results show that in comparison to the Control group, glucose clearance from the blood was more effective and rapid in the arginine-treated groups. This could mean that arginine induced rapid insulin-like action which was effective after thirty (30) minutes of oral glucose loading in both groups treated with arginine. L-arginine is the main endogenous source for the generation of nitric oxide (NO). A great body of evidence have shown that NO plays a critical role in glucose metabolism. NO is capable of stimulating glucose transport through GLUT-4 translocation in adipocytes, via a mechanism different from the insulin signaling pathway [13]. The administration of NO synthase (NOS) inhibitors induced remarkable insulin resistance [14]; NO donors stimulate glucose transport in skeletal muscles [15] and endothelial nitric oxide synthase (eNOS) knockout mice have insulin resistance [16]. L-arginine can also stimulate secretion of glucagon [17] which is another hormone that aids removal of glucose from the blood. Thus, NO and/or arginine may be an important modulator of glucose metabolism. Together, these findings suggest that NOstimulated glucose uptake in adipocytes occurs through an insulin-independent pathway [18].

Our results from this study showed rapid removal of glucose from the blood in the negative control group, this may be as a result of commensurate adiponectin expression as a result of the kidney injury. Adiponectin (APN) is a multifunctional cytokine that has an important role in the regulation of energy metabolism and inflammation [19]. Also Adiponectin has been described as an insulin-sensitizing adipokine that modulates glucose and lipid metabolism [20]. It also exerts pleiotropic actions, i.e. it promotes insulin 
sensitivity, inhibits cell death, and suppresses inflammation. It strongly suppresses hepatic gluconeogenesis by inhibiting the expression of genes involved in glucose production (such as phosphoenolpyruvate carboxykinase and glucose-6phosphatase) and enhances fatty acid oxidation in skeletal muscle, which together contributes to a beneficial metabolic action in whole body energy homeostasis [21]. Under physiological conditions, the circulating plasma concentrations of adiponectin in humans range from 2 to $20 \mathrm{mg} / \mathrm{ml}$ [22]. Therefore these studies support the suggestion that the expression of adiponectin in kidney injury may have caused insulin like actions in the regulation of blood glucose; hence the rapid and un-sustained removal glucose from the blood in the negative control group of animals.

Insulin tolerance test (ITT) is a simple method of detecting insulin resistance or measuring the sensitivity of target organs to insulin, as well as the rate of glucose clearance from the blood. From the study results, it is observed that in comparison to the control group, the other group of animals exhibit high fasted blood glucose levels (normal blood glucose concentration $=80-110 \mathrm{mg} / \mathrm{dl}$, elevated levels $=110$ $120 \mathrm{mg} / \mathrm{dl}$ ). This could be as a result of poor glucose handling caused by kidney injury.

Insulin resistance (IR) is characterized by resistance to the effects of insulin on glucose uptake, metabolism or storage. It is manifested by decreased insulin-stimulated glucose transport and metabolism in target tissue and by deficient suppression of hepatic glucose output [23]. Patients with acute kidney injury develop insulin resistance, and this is due to loss of kidney function [24], increased levels of insulin resistance-inducing adipokines such as tissue necrosis factor- alpha (TNF- $\alpha$ ) and leptin [25, 26], reduced secretion of insulin due to increased intracellular calcium (caused by parathyroid hormone imbalance $[27,28]$. Also, it was observed from the ITT result that glucose was more effectively and rapidly cleared from the blood in animals administered with high dose arginine compared to the control group; again indicating an insulin-like action of arginine.

From the GLUT-4 assay, L-arginine supplementation produced no marked difference in GLUT-4 expression across the various groups. Meaning that insulin-like activity observed may not be via the activation of GLUT-4 channels or exocytosis of GLUT4 proteins to the plasma membranes of insulin target organs. Acute kidney injury (AKI) is a common clinical condition that is associated with high morbidity and mortality; and Ischemia-reperfusion injury (IRI) is a common cause of AKI [29]. Various studies have suggested that adiponectin is up-regulated in the kidney in response to IRI and results confirmed that targeted disruption of adiponectin protects the kidney from IRI by suppressing apoptosis, inflammatory cell infiltration and pro-inflammatory molecule production in the kidney [30]. Therefore, it may be imperative to question if adiponectin expression had an impact on arginine inactivation of GLUT-4 channels. This may provide a reasonable explanation for why there was no significant difference in GLUT-4 expression across the various groups and in the calculated OGTT area under curve (AUC) across the groups in response to L-arginine supplementation.

\section{CONCLUSION}

The final results of this study showed that Larginine through nitric oxide pathway, exhibits a rapid but un-sustained insulin-like action in glucose metabolism by clearing glucose from the blood. Furthermore, the data from this study suggests that enhanced glucose handling and clearance by arginine is not via the activation of GLUT-4 channels on plasma membranes.

\section{ACKNOWLEDGEMENT}

Funding for the study was privately sourced. Authors listed contributed to conceptualisation, bench work and production of the manuscript. No conflict of interest is declared.

\section{REFERENCES}

1. Meyer, C., Dostou, J. \& Gerich, J., (1999). Role of the Human Kidney In Glucose Counterregulation. Diabetes, 48, 943-948.

2. Asano, T., Ogihara, T., Katagiri, H., Sakoda, H., Ono, H., Fujishiro, M., \& Uchijima, Y. (2004). Glucose transporter and Na+/glucose cotransporter as molecular targets of anti-diabetic drugs. Current medicinal chemistry, 11(20), 2717-2724.

3. Ricci, Z., Cruz, D. N., \& Ronco, C. (2011). Classification and staging of acute kidney injury: beyond the RIFLE and AKIN criteria. Nature Reviews Nephrology, 7(4), 201.

4. Andreelli, F., Jacquier, D., \& Troy, S. (2006). Molecular aspects of insulin therapy in critically ill patients. Current Opinion in Clinical Nutrition \& Metabolic Care, 9(2), 124-130.

5. Leyking, S., \& Fliser, D.(2014). Insulin resistance in CKD. Clin J Am Soc Nephrol; 9(4): 638-40.

6. Peters, H., \& Noble, N. A. (1996, November). Dietary L-arginine in renal disease. In Seminars in nephrology, 16(6): 567-575.

7. Jobgen, W. S., Fried, S. K., Fu, W. J., Meininger, C. J., \& Wu, G. (2006). Regulatory role for the arginine-nitric oxide pathway in metabolism of energy substrates. The Journal of nutritional biochemistry, 17(9), 571-588.

8. Jobgen, W. S., Fried, S. K., Fu, W. J., Meininger, C. J., \& Wu, G. (2006). Regulatory role for the arginine-nitric oxide pathway in metabolism of energy substrates. The Journal of nutritional biochemistry, 17(9), 571-588. 
9. Wu, J., Pan, X., Fu, H., Zheng, Y., Dai, Y., Yin, Y., Chen, Q., Hao, Q., Bao, D., Hou, D., (2017). Effect of curcumin on glycerolinduced acute kidney injury in rats. Sci Rep. 7(1):10114.

10. Yin, M., Jiang, N., Guo, L., Ni, Z., Al-Brakati, A. Y., Othman, M. S., ... \& Kassab, R. B. (2019). Oleuropein suppresses oxidative, inflammatory, and apoptotic responses following glycerol-induced acute kidney injury in rats. Life sciences, 232, 116634.

11. Baranowski, R. L., Westenfelder, C., \& Kurtzman, N. A. (1978). Intrarenal renin and angiotensins in glycerol-induced acute renal failure. Kidney international, 14(6), 576-584.

12. Leguisamo, N. M., Lehnen, A. M., Machado, U. F., Okamoto, M. M., Markoski, M. M., Pinto, G. H., \& Schaan, B. D. (2012). GLUT4 content decreases along with insulin resistance and high levels of inflammatory markers in rats with metabolic syndrome. Cardiovascular diabetology, 11(1), 100.

13. Balon, T. W., \& Nadler, J. L. (1994). Nitric oxide release is present from incubated skeletal muscle preparations. Journal of Applied Physiology, 77(6), 2519-2521.

14. Baron, A. D., Zhu, J. S., Marshall, S. T. E. P. H. E. N., Irsula, O. R. L. A. N. D. O., Brechtel, G. I. N. G. E. R., \& Keech, C. H. E. R. Y. L. (1995). Insulin resistance after hypertension induced by the nitric oxide synthesis inhibitor L-NMMA in rats. American Journal of PhysiologyEndocrinology And Metabolism,269(4), E709E715.

15. Balon, T. W., Nadler, J. L., \& (With the Technical Assistance of Arnie Jasman). (1997). Evidence that nitric oxide increases glucose transport in skeletal muscle. Journal of Applied Physiology, 82(1), 359363.

16. Duplain, H., Burcelin, R., Sartori, C., Cook, S., Egli, M., Lepori, M., ... \& Scherrer, U. (2001). Note Added in Proof. Circulation, 104(3), 342-345.

17. YOUNG, M. E., RADDA, G. K., \& LEIGHTON, B. (1997). Nitric oxide stimulates glucose transport and metabolism in rat skeletal muscle in vitro. Biochemical Journal, 322(1), 223-228.

18. Tanaka, T., Nakatani, K., Morioka, K., Urakawa, H., Maruyama, N., Kitagawa, N., ... \& Yano, Y. (2003). Nitric oxide stimulates glucose transport through insulin-independent GLUT4 translocation in 3T3-L1 adipocytes. European journal of endocrinology, 149(1), 61-67.

19. Karbowska, J., \& Kochan, Z. (2006). Role of adiponectin in the regulation of carbohydrate and lipid metabolism. Journal of Physiology and Pharmacology, 57, 103.

20. Tilg, H., \& Moschen, A. R. (2006). Adipocytokines: mediators linking adipose tissue, inflammation and immunity. Nature Reviews Immunology, 6(10), 772.

21. Wang, Z. V., \& Scherer, P. E. (2016). Adiponectin, the past two decades. Journal of molecular cell biology, 8(2), 93-100.

22. Turer, A. T., \& Scherer, P. E. (2012). Adiponectin: mechanistic insights and clinical implications. Diabetologia, 55(9), 2319-2326.

23. Samuel, V. T., \& Shulman, G. I. (2012). Mechanisms for insulin resistance: common threads and missing links. Cell, 148(5), 852-871.

24. Lee, S. W., Park, G. H., Lee, S. W., Song, J. H., Hong, K. C., \& Kim, M. J. (2007). Insulin resistance and muscle wasting in non-diabetic endstage renal disease patients. Nephrology Dialysis Transplantation, 22(9), 2554-2562.

25. Lang, C. H., Dobrescu, C. O. R. N. E. L., \& Bagby, G. J. (1992). Tumor necrosis factor impairs insulin action on peripheral glucose disposal and hepatic glucose output. Endocrinology, 130(1), 43-52.

26. Sweeney, G., Keen, J., Somwar, R., Konrad, D., Garg, R., \& Klip, A. (2001). High leptin levels acutely inhibit insulin-stimulated glucose uptake without affecting glucose transporter 4 translocation in 16 rat skeletal muscle cells. Endocrinology, 142(11), 4806-4812.

27. Fadda, G. Z., Hajjar, S. M., Perna, A. F., Zhou, X. J., Lipson, L. G., \& Massry, S. G. (1991). On the mechanism of impaired insulin secretion in chronic renal failure. The Journal of clinical investigation, 87(1), 255-261.

28. Levi, E., Fadda, G. Z., Thanakitcharu, P., \& Massry, S. G. (1992). Chronology of cellular events leading to derangements in function of pancreatic islets in chronic renal failure. Journal of the American Society of Nephrology, 3(5), 11391146.

29. Mehta, R. L., Pascual, M. T., Soroko, S., Savage, B. R., Himmelfarb, J., Ikizler, T. A., ... \& Program to Improve Care in Acute Renal Disease (PICARD. (2004). Spectrum of acute renal failure in the intensive care unit: the PICARD experience. Kidney international,66(4), 16131621.

30. Jin, X., Chen, J., Hu, Z., Chan, L., \& Wang, Y. (2013). Genetic deficiency of adiponectin protects against acute kidney injury. Kidney international, 83(4), 604-614. 